\title{
'Shakespeare in the bush' and encountering the other in the hermeneutical dialectic of belonging and distanciation
}

\author{
H C Waetjen \\ San Francisco Theological Seminary \\ Visiting Professor: University of Pretoria
}

\begin{abstract}
'Shakespeare in the bush' and encountering the other in the hermeneutical dialectic of belonging and distanciation

'Shakespeare in the Bush' is an account of an anthropologist's hermeneutical experience among the Tiv people of Nigeria that serves as an illustration of a hermeneutical circle which results in transforming the otherness of a text into the sameness of the prejudices and traditions projected by the preunderstanding in order to understand. This essay poses the hermeneutical objective of validity in interpretation by advocating an encounter with the otherness of the text that is orientated to the speech performance of the author, as it is conveyed by the textual structures of the implied author and the implied reader. Heidegger's and Gadamer's ontological condition of being-in-the-world and its projection of understanding are acknowledged as the only legitimate point of departure for interpretation. If alienating distanciation is to be evoked by an 'effective historical consciousness', a text must be read with the 'irony of interpretation' that interacts with it, the text, as both a speech performance (parole) and a linguistic code (langue).
\end{abstract}

Understanding is not simply a way of knowing; it is a priori a way of "being-in-theworld'. This, in essence, is the paradigm shift that hermeneutics has undergone during the past seventy years as a result of Martin Heidegger's unveiling of the ontological conditions of understanding. The fundamental reality of human existence is not 'being with', an orientation that would imply the question of the other and move the problem of understanding in the direction of epistemology (Ricoeur 1991:65-66). It is instead the reality of being-in-the-world, a condition that involves 'the power to be' which makes understanding possible. Dasein, with its Heideggerian characterization of 'being thrown' into a particular historical context with all of its traditions, norms and conventions, "has already projected itself and it remains in projection as long as it is' (Heidegger 1927:145; 1962:185). Understanding is primordially this projection of Dasein, of being-in-the-world, and its basic function is 
to orient the self as it inhabits the world with its fundamental sense of 'belonging to' (Zugehörigkeit). As an ontological reality, therefore, understanding is not the result of interpretation; rather understanding precedes interpretation and indeed makes interpretation possible.

Formerly, however, hermeneutics in its revolutionary 19th century development under Schleiermacher and Dilthey was established with an orientation toward 'being with' that implied a dialogical relationship between an interpreter and a subjectivity that had externalized itself in a text. The hermeneutical objective was the reconstruction of the other's thought expressed in the text. The operations of understanding in relation to the interpretation of the text was determined by a technology of methodology which, according to Age of Enlightenment ideology, was substituted in place of prejudice, tradition, and authority and therefore guaranteed the objectivity of the enterprise and the truth of its results.

But the epistemology of Cartesian dualism with its foundational purification of the mind, even in its Kantian reconstitution, is unable to establish an ultimate grounding for the human sciences. No Kantian or neo-Kantian critique can provide an epistemological foundation for the operations of a hermeneutics that is oriented toward an understanding of the other on the basis of 'being with' for the simple reason that the recovery of the mental life of an other by psychological explanation is scientifically impossible (Ricoeur 1991:56-63) ${ }^{1}$. Moreover, methodology is unable to operate neutrally because prejudices and preconceptions cannot be bracketed in the preunderstanding, and in fact they determine the questions addressed to the text as well as the methodology employed for interpretation (Gadamer 1975a:285; 1975b:269; 1979:151-152).

The hermeneutics of 'being with' an other ironically required the arbitrary distanciation of neutrality. With a priori alienation (Verfremdung) from the text as the starting point, the intelligibility of mind, laboring in and through methodology, would transport the interpreter into the realm of another time and place and by the determination of meaning in relation to a specific historical context would illuminate the obscure text. Understanding would finally be achieved by means of the technology of interpretation.

The reality of being-in-the-world, however, is prior to 'being with' an other, and the understanding it projects precedes interpretation. At the same time the condition of 'belonging to' (Zugehörigkeit) ontologically supersedes alienating distanciation (Verfremdung) as a fundamental presupposition of hermeneutical theorizing. Understanding and 'belonging to' are concomitant realities of the ontological ground of being-in-the-world. As Paul Ricoeur (1991:72) has expressed it: 'History precedes me and outstrips my reflection; I belong to history before belonging to myself. 
Consequently the prejudices and traditions acquired in and through a prereflective belonging to history constitute the understanding, or rather the preunderstanding, which the self projects to orient itself in the world. This projection of the preunderstanding is an event, a happening; and it is universal (Ricoeur 1991:70-74). No understanding is possible without the projection of the prejudices and traditions of the preunderstanding. Some of them are blinding and distort the subsequent activity of interpretation; others are berechtigt, justifiable, because they promote intelligibility and perspicacity (Gadamer 1975a:263; 1975b:247-249). Discriminating between them is a developmental process that occurs in and through the experience of testing them in the activity of interpretation.

While 'belonging to' is the a priori hermeneutical condition, alienating distanciation is its dialectical opposite and, according to Gadamer, is engendered by the interpreter's 'effective historical consciousness' (wirkungsgeschichtliches Bewusstsein). That is, 'effective historical consciousness' makes the reader aware of the finitude of her or his horizon with its inherent limitations of vision and simultaneously therefore also of an alienating distance from the text (Gadamer 1975a:286; 1975b:269). Or, to use the words of Paul Ricoeur (1991:35): 'To interpret is to render near what is far (temporally, geographically, culturally, spiritually).' Dasein naturally orients itself to any text and with its projection of preunderstanding initiates the interpretive process. 'Belonging to' negates all neutrality and objectivity, but possibly also alienating distanciation, as the interpreter is drawn into the text and the play of interaction begins. The text's alterity will only be experienced if the dialectical dynamic of 'belonging to' and 'alienating distanciation' has been activated by 'effective historical consciousness'.

Distanciation, according to Paul Ricoeur (1991:75-88), is a natural property of all speech events, oral and written. At least two occurrences of this condition may be differentiated in the movement from oral discourse to the reading of a text. The first happens in the passage from language (langue) to speech (parole): 'from the linguistics of a code to the linguistics of a discourse' (Ricoeur 1991:77). Someone makes an utterance, says something about something, sends a message to another person. As language is actualized in speech in order to express meaning, a linguistic event takes place. The event itself is transitory, and it is surpassed by the utterance that was spoken. In the difference between what is said (the message) and the saying of it (the event) the first distanciation occurs. The message with its fullness of meaning may linger on into the future, but distance will be constituted between the event and the message itself. 
While this may be true, what is at least equally significant is the closed and determinate construal of meaning at the time of the speech event. The speaker and the hearer share one and the same context. No distanciation is experienced. The condition of 'belonging to' and the projection of the prejudices and traditions of the preunderstanding engender immediate understanding facilitated by the constitutive elements of context, code, and contact.

The same appropriation of meaning may also occur in conjunction with the second kind of distanciation that Ricoeur identifies, the exteriorization of discourse in the inscription of a work - a written speech event. Sentences are joined together to form a composition whose identity is determined by the author's choice of a specific genre: poem, novel, letter, gospel, etc. This too is an event, an event of labor and production in response to a particular situation or circumstance, and it is individuated by the author's style and organization of material. A text comes into being, and as it leaves its author's control, it assumes an autonomy of its own, independent of authorial will. The work has surpassed the event of its composition. Yet before it transcends its original context and becomes subject to polysemy, its meaning is determinate and closed to its original addressees who share the same horizon with the author. In spite of the absence of authorial regulation and the distanciation produced by the intermediate contact with a written work, there is a genuine occurrence of rendering near what is far. While the message may be rejected, its meaning, the subject matter which the author intended to communicate, facilitated by the shared socio-cultural context and linguistic code, is appropriatable. Very little, if any, 'effective historical consciousness' is required for the actualization of understanding. However, as distanciation increases in terms of time, sociocultural contexts, and linguistic codes, the alterity of the text becomes opaque and therefore subject to polysemy. Accordingly, 'effective historical consciousness' becomes indispensable in summoning explanation as primordial understanding extends itself into interpretation and by the fusion of horizons attempts to render near what is far.

A consciousness formed by the authentic hermeneutical attitude will be receptive to the origins and entirely foreign features of that which comes to it from outside its own horizons.

(Gadamer 1979:151-152)

But what is the alterity of the text? It is not simply the fact of the text itself as an objective, autonomous reality2. Textual otherness consists in the message or subject matter which the text conveys. But that begs the critical question: what is the message of the text? Is it what the author intended to say or what the text is about? This is Ricoeur's dichotomy, and it is crucial to his hermeneutical synthesis. It 
correlates with his differentiation between the ostensive references of the text to its original context (Umwelt) and the nonostensive references which are identified with 'the kind of world (Welt) opened up by the depth semantics of the text' (Ricoeur 1991:87-88, 165). The relationship of sign to referent and the relationship of sender and receiver respectively do not produce the meaning that Ricoeur identifies as 'the world in front of the text'. What the text is about is a possibility of being, and this is communicated both unconsciously and consciously to the reader, while engaged with the written discourse (parole) by the generational capabilities of the linguistic code (langue) through the relations of contiguity and the accompanying principles of combination as well as the accompanying principles of selection ${ }^{3}$. Depth semantics is 'the product of perceptual structures which operate in the [author's] mind at an unconscious level rather than at a consciously artistic level' (Wittig 1977:82). Concomitantly the semantic universe of the reader is presumed to be 'conditioned to receive and decode the message at this unconscious level' (Wittig 1977:82). The projection of preunderstanding perceives 'the world of the work' which the text discloses and confronts the subjectivity of the reader with 'figures of liberation', that is, a new possibility of being. Understanding, therefore, is realized by 'exposing ourselves to the text and receiving from it an enlarged self', not 'by imposing upon the text our finite capacity for understanding' (Ricoeur 1991:88). At the same time, however, there is also a conscious movement 'from sense to reference, from what the text says to what it talks about'; and this involves the movement from explanation to understanding. All the semiological systems, along with the linguistic system, must be decoded, and, as Ricoeur says, 'that requires a special affinity between the reader and the kind of things the text is about' (Ricouer 1991:164). What is appropriated is not a system of ideas but deep values of truth that are imposed with such power that no further proof is needed to perceive their validity and reality' (Patte \& Patte 1978:101).

But is the alterity of the text to be identified only with depth semantics, with Ricoeur's world in front of the text'? What has happened to the message which the author intended to communicate to the original addressees? Is the speech (parole) of the author, as a result of natural distanciation, to be completely identified with langue, the linguistic code of the text? If distanciation prevents the appropriation of every trace of affective affinity with the intention of the author, that would indeed exclude the mental life of the author (see Ricoeur 1991:87). But the intention of the author is also a textual reality, expressed in the message which continues to be embedded in the text by the design of the author. 
The text may be presented to its readers at face value simply as the literary structure of a linguistic code (langue), but its otherness includes an authorially originated speech performance (parole). The fullness of its subject matter is conveyed as a dialectical textual reality of both the written discourse (parole) of the author and the linguistic code which the author has employed. Differentiating between them and determining their nascency is a hazardous subjective undertaking. Metaphorical, symbolic and allegorical meanings are attributable to both authorial will (parole) and linguistic sense (langue). Whether by authorial design or linguistic polysemy, Dasein's primordial conditions of Zugehörigkeit and its projection of its circular structures of preunderstanding naturally appropriate both, often simultaneously. Even in a circumstance involving two separate contexts or horizons, that of the text itself and that of its readers temporally, linguistically and culturally removed from it, distanciation cannot prevent appropriation from experiencing affective affinity with the fullness of the otherness of the text.

The dialectical textual reality of written discourse (parole) and linguistic code (langue) engenders the great irony of interpretation (Hunter 1992:69; 1989:229$243)^{4}$. For, on the one hand, Dasein's primordial reality of being-in-the-world and its condition of 'belonging to' will naturally be inclined to fix itself on the latter (langue) and to understand the sense of the textual signs in terms of the prejudices and traditions of its preunderstanding. Yet on the other hand, there is the textual reality of the author's discourse (parole) that conveys the subject matter of the authorial-willed message. All too often, however, the irony of interpretation remains unfulfilled. Dasein's condition of 'belonging to' does not always activate 'effective historical consciousness' and its attendant awareness of distanciation, and therefore the otherness of the text is never encountered.

In this regard, Bohannan's article, Shakespeare in the bush (Bohannan 1966) is a case in point, although in many ways of limited value. Laura Bohannan, an anthropologist from the University of Illinois, offers a delightful account of a hermeneutical experience in the bush which illustrates the operation of Dasein's ontological reality of 'belonging to'. While studying Hamlet in the West African bush, she was invited to drink beer and share a story with a small group of elders of the Tiv people. Presupposing that there was only one possible interpretation of Hamlet, she decided to test her theory by narrating the story of Shakespeare's tragedy. Throughout her narration she was continuously interrupted by the elders who interpreted the story in terms of the prejudices and traditions which their preunderstanding projected without any apparent consciousness of alienating distanciation. One instance will perhaps suffice as an example. To quote Bohannan as she begins her recounting of that experience: 
The old man handed me some more beer to help me on with my story-telling. Men filled their long wooden pipes and knocked coals from the fire to place in the pipe bowls; then puffing contentedly, they sat back to listen. I began in the proper style. 'Not yesterday, not yesterday, but long ago a thing occurred. One night three men were keeping watch outside the homestead of a great chief, when suddenly they saw the former chief approach them.' 'Why was he no longer their chief?' 'He was dead,' I explained. 'That is why they were troubled and afraid when they saw him.' 'Impossible,' began one of the elders, handing his pipe to his neighbor who interrupted. 'Of course it wasn't the dead chief. It was an omen sent by a witch. Go on!

(Bohannan 1966:57)

In this manner the story-telling continued with frequent interpolations and corrections until the narrative ended. The entire episode, according to Bohannen, was closed by the old chief:

Sometime you must tell us more stories of your country. We, who are elders, will instruct you in their true meaning, so that when you return to your own land your elders will see that you have not been sitting in the bush, but amongst those who know things and who have taught you wisdom.

(Bohannan 1966:60)

Gabriele Schwab (1992), in her analysis of this hermeneutical event in the bush, acknowledges that the elders 'recreated their own cultural pattern within Shakespeare's plot' but concludes, 'The Tiv people had to project their own cultural preconceptions in order to reduce the otherness that would have made Hamlet incomprehensible in their context' (Schwab 1992:127) ${ }^{5}$. But is the story so alien and strange that it has no affinity with the culture and experience of the Tiv people? Of course, the village elders, as guardians of the community's traditions and their interpretation, may be constrained to remain within the context of their Dasein and its project. Consequently, any 'effective historical consciousness' that might have emerged from their primordial condition of 'belonging to' to make them aware of their distinctive vantage point and to open their horizon to the otherness of the story may have been suppressed by the perspective of their hierarchical position in the Tiv polity. In any case, no sense of distanciation manifested itself to initiate an interrogation of the details of the story and to solicit explanation. The world of the text (Welt) did not explode the world (Umwelt) of the author. The preunderstanding 
of Zugehörigkeit simply projected its own determinate meaning on the linguistic code of the text, producing a vicious hermeneutical circle which resulted in 'the recreation of their own cultural pattern' (Schwab 1992:110). Otherness was transformed into sameness (Schwab 1992:117).

Understanding is not the reduction of a literary composition to congruency with one's own prejudices and traditions. It is rather a closure of meaning that has involved an encounter with the otherness of the text. In spite of the skepticism of deconstruction, Gadamer's characterization of the ontology of literary texts seems to be a principle that holds priority over the reality of Jacques Derrida's différance and its dispersion and deference of meaning. 'Understanding belongs to the meaning of a text just as being heard belongs to the meaning of music. The meaning of all texts is realized when they are understood' (Gadamer 1975a:156; 1975b:146) ${ }^{6}$. If understanding is a closure of meaning, how is understanding attained beyond the mere projection of Dasein's 'belonging to'?

Umberto Eco's (1983) maxim, 'Stat rosa pristina nomine, nomina nuda tenemos', which stands as the closure of his novel, The name of the rose, is as valid a starting point as any other (Eco 1983:502). Construing meaning begins by recognizing that 'we grasp the name empty'. That is, the empty linguistic signs of a text are automatically filled by the projection of Dasein's preunderstanding. Being-in-theworld and its 'belonging to' necessitate the orientation of the self, but this may be nothing more than reading the text as a code of linguistic signs (langue). If understanding is a closure of meaning that includes an encounter with the alterity of the text, how can the production of meaning comprehend the complexity of the text as both a 'cultural speech performance' (Schwab 1992:111) and a code of linguistic signs?

The former, the text as parole or speech performance, bears its own set of difficulties. Schleiermacher's aphorism of his 1805 and 1809 lectures: 'Each word has properly only one meaning - even particles - and one does not understand the variables without reduction to the original unity.' Parole, the speech performance of an individual, is a delimiting use of language in which the linguistic signs that are employed bear a single, determinate sense regulated by the consciousness of the author. Nevertheless, at the same time, because of the dynamic relationship between the signifier and the signified, authors may say more than they intend, more than they are conscious of. Accordingly, authorial control cannot be exercised over the construal of meaning, even within a linguistic and socio-cultural context shared by both author and reader. When two contexts or horizons are involved, that of the text and that of the reader, the fusion of horizons becomes a formidable undertaking. Of course, to be repetitive, that fusion is not the assimilation of one horizon 
into another, but the extension of the preunderstanding's projection to construe the text as both a cultural speech performance and a dynamic code of linguistic signs. While otherness is concentrated in the former (parole), it is extended by the potency and instability of the latter (langue).

A text, therefore, is understood and its meaning is realized when it, the text, is interpreted ironically; that is, when the reader is engaged in a play with both textual realities, speech performance (parole) and linguistic code (langue) and through the process of interaction gradually experiences the otherness of the text. Alienating distanciation, vital to this process of interaction, can be evoked by Dasein's projection of 'effective historical consciousness' if a sense of irony is appropriated as an a priori approach to all texts. That involves the acquisition of two sets of ears, one that hears the surface meanings of the linguistic code and one that penetrates the surface to listen to the voice of 'the implied author', namely those marks of the actual author's subjectivity that have externalized themselves in the text.

For very likely the text, on a first reading - or more - does not mean what it says, if only because of a more immediate orientation of Dasein's condition of 'belonging to' toward the text as a code of linguistic signs. Here is where a hermeneutics of suspicion can operate effectively, enabling the reader to read 'against the grain'7. The objective is to determine how the text as a linguistic code (langue) stands in the service of the speech performance. The richness of the relationship between the two, speech performance and linguistic code, with all the nuances and allusions which the latter provides, those by the design of the author and those by the creative interaction of the reader, can only be realized by an ironic discernment that is critical of Dasein's projection of its preunderstanding.

For, as Heidegger characterized it, human being is a condition of 'thrownness', and the sense of finitude which it evokes generates the anxiety about being-in-theworld as well as the anxiety of being-in-the-world. That is, the fear of death and the fear of life. On the one hand, the determinism of finitude must be overcome; on the other hand, the infinitude of life and freedom must be controlled. The existential paradox of finitude and infinitude and its creative possibilities are negated by the narcissistic search for power and security. Defensive mechanisms are established to shut out the contingencies and threats of otherness and concomitantly to maintain the peace and safety of sameness.

Accordingly, the same irony of interpretation must be directed at the self's preunderstanding in order to expose those prejudices and traditions which maintain the mechanisms of insulation. The openness to otherness is a condition of inestimable possibility for self-affirmation and self-realization and therefore also the fulfillment of human destiny. That primordial understanding of being-in-the-world, 
by which human beings orient themselves as they inhabit the world, must be unmasked. Dasein's project must become critically conscious of itself; it must 'read itself against the grain'8. It is only a 'reflected projection' that produces 'a capacity for otherness' as otherness is encountered in both individuality and multiplicity (Schwab 1992:129).

If understanding is a closure of meaning that requires the irony of interpretation to develop an openness to textual otherness, the text itself must not be regarded as a shell-like container from which its otherness can be extracted as a 'thing'. The alterity of the text, which is identifiable with the subjectivity that has externalized itself in the text in order to communicate a message, is a potentiality that is inherently present in the signs of the linguistic code the author has employed. Those signs or words designate the instructions to the reader for the production of the signified.

The text itself simply offers 'schematized aspects' through which the subject matter of the work can be produced, while the actual production takes place through an act of concretization. From this we conclude that the literary work has two poles, which we might call the artistic and the aesthetic: the artistic pole is the author's text and the aesthetic is the realization accomplished by the reader. In view of this polarity it is clear that the work itself cannot be identical with the text or with the concretization, but must be situated somewhere between the two.

(Iser 1978:21)

The reader and the text are partners collaborating as co-creators in an aesthetic event of understanding that, by generating an experience of meaning, originate something that did not exist before.

If the play of interaction has occurred with an 'effective historical consciousness' that has realized a 'fusion of horizons', that something is a new 'subjectivity' (Schwab 1992:114) that combines the subjectivities of the author and the reader. Consequently, if this is the valid result of understanding's projection of interpretation, no identical productions of meaning can ever be actualized. But this is not because the text is polysemous - although it is that if simply approached as a structured linguistic code (langue) - but rather because the text, with its authorial instructions, and the reader, with her or his distinctive Dasein and its project, have united in a collaborative effort to create something new.

Unlimited multisignification, however, cannot be justified. Not every production of meaning that may result from this aesthetic interaction is valid. Unless there is an exchange, a transaction with the textual realities of 'the implied author' and 'the implied reader', the otherness of the text will not be encountered. 
The former, the implied author, is 'a system of perspectives designed to transmit the individuality of the author's vision' (Iser 1978:35). More concretely, it is the sum total of all the decisions an author has made to externalize his or her subjectivity in a literary work in order to communicate a message: choices of narrator, genre, plotline, characters and characterization, repertoire, and rhetorical strategies (Iser 1978:53-103).

What they do is provide guidelines originating from different starting points (narrator, characters, etc.) continually shading into each other and devised in such a way that they all converge on a general meeting place.

(Iser 1978:35)

Anticipated by the author, of course, is a reader who is 'offered a particular role to play, and it is this role that constitutes the concept of the implied reader' (Iser 1978:34-35). As a textual construct laid down by the author, the implied reader 'embodies all those predispositions necessary for a literary work to have its effects' (Iser 1978:34).

The more acutely the actual reader can perceive that 'network of responseinviting structures' of the implied reader and fulfill that role as designed by the author, the more adequate the construal of meaning will be. Indeed, validity in interpretation can only occur when the otherness of the text, as it is conveyed by the textual structures of the implied author and the implied reader, is realized by the structured acts of the actual reader.

The literary work itself, as a result of the author's creativity, is a 'world' of its own, a construction of reality that to a limited extent mirrors the socio-cultural context in which it was created or a particular socio-cultural 'world' determined by the choice of repertoire. Because of the selectivity involved in its construction, it is never a reproduction of the empirical world. The deliberate rearrangement of the social norms and traditions is aimed at producing defamiliarization and restructuring the preunderstanding's perception of reality.

It is the way in which this world is constructed that brings about the perspective intended by the author. Since the world of the text is bound to have variable degrees of unfamiliarity for its possible readers (if the work is to have any 'novelty' for them), they must be placed in a position which enables them to actualize the new view.

(Iser 1978:34)

This new view is the essence of otherness which a competently created text intends to communicate and which in turn anticipates a competent reader for its realization. 
A consciousness formed by the authentic hermeneutical attitude will be receptive to the origins and entirely foreign features of that which comes to it from outside its own horizons. The hermeneutical attitude supposes only that we self-consciously designate our opinions and qualify them as such, and in so doing strip them of their extreme character. In keeping to this attitude we grant the text the opportunity to appear as an authentically different being and to manifest its own truth over and against our preconceived notions.

(Gadamer 1979:151-152)

The text as an authentically different being results from the author's creative and discriminating speech performance combining linguistic code, genre, style, repertoire and rhetorical strategies. Many or even most of these choices are, of course, time-bound, determined by the socio-cultural context in which the literary work was produced. A genuine fusion of horizons will require the utilization of methods and models derived from other academic disciplines to serve as extensions of Dasein's project. 'Effective historical consciousness' operating in and through philological and historical investigation, augmented by the social sciences, will elucidate the horizon of the text and explicate the socio-cultural idiosyncrasies of its repertoire.

The alterity of the text, however, is not to be identified with the socio-cultural, economic or religious realities which its linguistic code and repertoire reflect. Vital explanations and elucidations of these realities are produced by the utilization of the theories, models and methods of the social sciences, but, while they enhance the interpretation of the text, they do not represent the otherness of the text. Objectifications of textual and contextual reconstructions, resulting from the employment of the social sciences, are always a posteriori undertakings after the eventful experience of Dasein's 'belonging to' has mediated alienating distanciation through 'effective historical consciousness' and has constituted a fusion of horizons. The resulting representation of objects can be nothing more than probable conclusions and approximations, for the new subjectivity that has been produced through the interaction of text and interpreter can never become universally true. The knowledge or truth claims that have been constituted are valid for that moment in time (Hunter 1992:65), but will eventually be superseded by the generation of a new subjectivity produced by another interaction between the text and the interpreter.

However, the truth claims of any interpretation remain deficient and therefore invalid unless they have emerged from an encounter with the otherness, the subject matter, of the text. That implies the operation of a dialectical hermeneutical circle that rotates through 'belonging to' and alienating distanciation while interrelating 
with the textual structures of the implied author and the implied reader and simultaneously incorporating the technology of methodology offered by the social sciences and rhetorical criticism. In this playful interaction with the text and in dialogue with its subject matter the reader/interpreter fulfills the being of the literary work by actualizing its potentiality of meaning. Having begun with a hermeneutics of being-in-the-world, the reader/interpreter culminates the interpretive project with a hermeneutics of 'being with' an other in dialogue.

Paul Ricoeur (1991:70), dissatisfied with the one-way street of Heideggerian ontology that prevents 'repeating the epistemological question after ontology', attempts to construct a return thoroughfare back to epistemology.

With Heidegger's philosophy, we are always engaged in going back to the foundations, but we are left incapable of beginning the movement of return that would lead from the fundamental ontology to the properly epistemological question of the status of the human sciences.

(Ricoeur 1991:69)

The ultimate objective of his hermeneutics, like that of Hirsch, is the attainment of validity in interpretation'. 'A text is a limited field of possible constructions' and '...not all interpretations are equal' (Ricoeur 1991:160). Validation involves testing the projection of good guesses by determining the probability of the 'verbal intention of the text'. This is subject to judicial reasoning as all interpretations are brought before a public tribunal of judgment. But the procedures of appeal are never exhausted. 'Neither in literary criticism, nor in the social sciences, is there such a last word' (Ricoeur 1991:162). Nevertheless, Ricoeur still insists,

A text is a quasi individual, and the validation of an interpretation applied to it may be said with complete legitimacy to give a scientific knowledge of the text.

(Ricoeur 1991:159)

Although a text may be considered as a quasi individual, Ricoeur, on his road back to epistemology, avoids any renewal of contact with the hermeneutics of 'being with' which Schleiermacher had formulated. 'Depth semantics constitutes the genuine object of interpretation...' (Ricoeur 1991:164) and this conducts the interpreter into a world of semiotic systems and structural analysis.

‘...understanding has nothing to do with an immediate grasping of a foreign psychic life or with an emotional identification with a mental intention. Understanding is entirely mediated by the whole of explanatory procedures that precede it and accompany it. The counterpart of this personal appropriation is not something that can be felt, it is 
the dynamic meaning released by the explanation which we identified earlier with the reference of the text, that is, its power of disclosing a world.

(Ricoeur 1991:167)

Ricoeur's 'world in front of the text', which he identifies with the depth semantics of the text, is a world of logocentrism, a world in which the linguistic code of a text, functioning as a semiotic system, has the power to communicate apart from and even in spite of the author's intention.

To what extent, then, has he succeeded in escaping Heideggerian ontology? Language for nim, as for Heidegger, is the house of being which by a dialectical movement of the hermeneutical circle through understanding and explanation and explanation and understanding will disclose new possibilities of being (Ricoeur 1991:156-167).

But the textual structures of the implied author and the implied reader continue to convey the presence of an author (Iser 1978:35; see also Booth 1983:16-20). The author, therefore, cannot simply be abolished from the text on the basis of a hermeneutical theory that rejects the recovery of authorial will. While interpretation must legitimately begin with a hermeneutics of Dasein and its projection of preunderstanding's prejudices and traditions, ideologies and methodologies, it must eventually return to a hermeneutics of 'being with' an other. Not the other as a psychic life that is to be re-experienced and reconstituted, but the other as a vision or a truth conveyed by the speech performance of an author in terms of a potentiality structured in the text that can only be actualized through the process of reading.

It is in the reader that the text comes to life, and this is true even when the 'meaning' has become so historical that it is no longer relevant to us.

(Iser 1978:19)

In the dialectic of the hermeneutics of being-in-the-world and the hermeneutics of being-with-an-other there is a movement away from the individuality and isolation of the thrownness of being-in-the-world into a dialogical relationship with an other. Even if that other, materially speaking, is only a text, its subject matter establishes the possibility of a dialogue which not only marks the beginning of community and the collaborative and creative enterprise of generating something new. Moreover, that which is new - a new subjectivity! - poses the possibility of experiencing a defamiliarization of the reality structures of being-in-the-world and with it an actualization of a new self-awareness that is both liberated and liberating. 
The truth that emerges in and through this new subjectivity, generated by the interaction between text and reader may be ephemeral, exerting its claim for but a moment. But if it should become embodied in the flesh and blood life of the reader, it will in turn realize a new potentiality: the transformation of the reader's self and the world to which that self belongs. The ultimate objective of the otherness of texts is not merely the establishment of the truth of ideas and concepts as objects for the contemplation of the intellect but its objectification in actions and deeds that constitute integrity and contribute to change in the world.

\section{END NOTES}

1. As, for example, was attempted by Wilhelm Dilthey.

2. Of course, there are some, like Stanley Fish (1980), who deny the objectivity and therefore also the autonomy of the text.

3. Although Ricoeur does not state this explicitly, he does speak of structuralism's analysis of depth semantics, and this is generally the focus of structural analysis (see also Wittig 1977:81).

4. Hunter (1992:69; 1989:229-243) speaks of the 'irony of meaning', whereas I prefer to speak of the 'irony of interpretation'. He focuses on the text's problematic of intentional and unintentional meaning; $I$ on the attitude and approach to the text by the reader/interpreter in view of this textual problematic.

5. My thanks to Gregg Lambert for calling my attention to this seminal essay.

6. What Gadamer has formulated as questions, I have taken the liberty, on the basis of his own answers, to reconstitute as statements.

7. See Schwab's (1992:121-122) application of Lacan's hermeneutical perspective to the problematic of encountering the otherness of the text.

8. See Schwab's (1992:121-122) discussion of Lacan's analysis of 'the other'.

9. See Ricoeur's (1991:158-162) discussion of the problem of validation vis-a-vis Hirsch.

\section{Works consulted}

Bohannan, L 1966. Shakespeare in the bush. Natural History 75, $28-33$.

Booth, W 1983. The rhetoric of fiction. Chicago: University of Chicago Press.

Eco, U 1983. The name of the rose. New York: Harcourt.

Fish, S 1980. Is there a text in this class? The authority of interpretive communities. Cambridge: Harvard University Press. 
Gadamer, H G 1975a. Wahrheit und Methode. Tübingen: Mohr.

- 1975b. Truth and method. Tr by G Barden \& J Cumming. New York: Seabury Press.

- 1979. Problem of historical consciousness, in Rabinow, P \& Sullivan, W L (eds), Interpretive social science: $A$ reader, 107-152. Berkeley: University of California Press.

Heidegger, $M$ 1927. Sein und Zeit. Halle: Niemeyer.

- 1962. Being and time. Tr by J Macquarrie \& E Robinson. London: SCM Press.

Hunter, J H 1989. The irony of meaning: Intertextuality in Hebrew poetical texts. Joumal for Semitics 2, 229-243.

- 1992. Escaping the abyss: Beyond deconstruction in Old Testament studies. Acta Academica 24/3, 62-76.

Iser, W 1978. The act of reading: $A$ theory of aesthetic response. Baltimore: John Hopkins University Press.

Patte, D \& Patte A 1978. Structural exegesis: From theory to practice. Philadelphia: Fortress Press.

Ricoeur, P 1991. From text to action: Essays in hermeneutics, II. Evanston: Northwestern University Press.

Schwab, G 1992. Reader-response and the aesthetic experience of otherness. Stanford Literature Review 3, 107-136.

Wittig, S 1977. A theory of multiple meanings. Semeia 9, 75-103. 